\title{
DEPRESSION IN CHRONIC MIGRAINE
}

\section{Severity and clinical features}

\author{
Juliane Prieto Peres Mercante ${ }^{1}$, Mario Fernando Prieto Peres², \\ Vera Guendler ${ }^{1}$, Eliova Zukerman², Marcio Antonini Bernik ${ }^{3}$
}

\begin{abstract}
Introduction: Chronic migraine (CM) is a common medical condition affecting $2.4 \%$ of the general population. Depression is one of the most frequent comorbid disorders in CM. Method: Seventy patients diagnosed with chronic migraine were studied. All patients evaluated filled out the Beck Depression Inventory (BDI). Depression severity was divided into none or minimal depression, mild, moderate, and severe. Results: BDI ranged from 4 to 55 , mean $21 \pm 10.7$. Moderate or severe depression, were present in $58.7 \%$ of the patients. Some degree of depression appeared in $85.8 \%$ of patients. The BDI scores correlated with pain intensity $(p=0.02)$. Severe depression was more frequent in patients with comorbid fibromyalgia and in patients reporting fatigue. Conclusion: The BDI is an easy tool to access depression in CM patients. Suicide risk assessment is needed in CM patients. Patients with fibromyalgia and fatigue are at even higher risk for severe depression.
\end{abstract}

KEY WORDS: chronic migraine, comorbidity, depression, suicide.

\begin{abstract}
Depressão em migrânea crônica: aspectos clínicos e gravidade
RESUMO - Introdução: A migrânea crônica (MC) é uma doença comum, que afeta $2,4 \%$ da população geral. A depressão é uma das comorbidades mais frequentes em enxaqueca. Método: Setenta pacientes diagnosticados com migrânea crônica foram estudados. Todos os pacientes preencheram o Inventário de Depressão Beck.(BDI). A gravidade da depressão foi dividida em nenhuma ou leve, mínima, moderada, e grave. Resultados: O BDI variou de 4 a 55, média $21 \pm 10,7$. A depressão moderada ou grave esteve presente em $58,7 \%$ dos pacientes. Algum grau de depressão foi observado em $85,8 \%$ dos pacientes. Os escores de depressão correlacionaram-se com a intensidade da dor. A depressão grave foi mais freqüente em paciente com comorbidade com fibromialgia e fadiga. Conclusão. O BDI é um instrumento de fácil avaliação da depressão em MC. A identificação do risco de suicídio é necessária nestes pacientes. Fibromialgia e fadiga são fatores de risco para depressão grave.
\end{abstract}

PALAVRAS-CHAVE: migrânea crônica, comorbidade, depressão, suicídio.

Chronic migraine (CM) is the most common of the the chronic daily headaches, a heterogeneous medical condition defined as headaches at least 15 days each month for more than three months, and also includes chronic tension-type headache, hemicrania continua, and new daily persistent headache'. $\mathrm{CM}$ affects $2.4 \%$ of the general population ${ }^{2}$ and accounts for most consultations in headache clinics ${ }^{3}$. Because $\mathrm{CM}$ affects people during their peak productive years, it imposes a significant decrease in their social functioning and quality of life and there is a considerable economical burden to society ${ }^{4}$.
Migraine and psychiatric disorders, specially depression, overlap in different clinical and epidemiological aspects. From a clinical perspective, premonitory symptoms of migraine attacks often include psychiatric symptoms, such as depression, elation, irritability, anxiety, overactivity, difficulty thinking, anorexia or increased appetite. Also, CM is commonly comorbid with other conditions. Depression is one of the most frequentely reported (up to $80 \%$ ), followed by anxiety $(70 \%)^{5}$, insomnia $(71 \%)^{6}$ and other medical conditions such as chronic fatigue $(66 \%)^{7}$, and fibromyalgia $(35 \%)^{8}$.

\footnotetext{
'Psicóloga, pesquisadora do Instituto de Ensino e Pesquisa do Hospital Israelita Albert Einstein, São Paulo SP, Brasil (HIAB); ${ }^{2}$ Médico Neurologista, HIAB; ${ }^{3}$ Médico psiquiatra HIAB e do Hospital das Clinicas da Faculdade de Medicina da Universidade de São Paulo (FMUSP), São Paulo SP, Brasil.
}

Received 31 May 2004, received in final form 15 October 2004. Accepted 29 November 2004.

Dra. Juliane Prieto Peres Mercante - Al. Joaquim Eugenio de Lima 881 / cj 708 - 01403-001 São Paulo SP-Brasil. E-mail: julianeperes@ terra.com.br 
In two epidemiological studies, one from Zurich, Switzerland ${ }^{9}$, and one from Detroit USA ${ }^{10}$, a clear relationship between migraine and major affective disorders has been found ${ }^{11}$. In the Zurich study, people with migraine had twofold-increased prevalence of major depression (15\% versus $7 \%$ ). However, little is known about the range of severity of depressive symptoms in chronic migraine patients.

The objective of this study was to access the clinical spectrum of depression and its severity in chronic migraine patients.

\section{METHOD}

Seventy consecutive patients from the Albert Einstein Hospital, Sao Paulo and São Paulo Headache Center, Sao Paulo, Brazil, diagnosed with chronic migraine according to Silberstein et al. ${ }^{1}$ diagnostic criteria were included in the study. All patients also fit diagnostic criteria for chronic migraine according to the revised International Classification of Headache Disorders ${ }^{12}$. Physical and neurological examinations were done in all patients. Appropriate investigation was performed in suspected cases. Patients with secondary headaches or other primary headache disorders were excluded.

Initial assessment included sixty-three women (90\%) and 7 men (10\%). Age varied from 16 to 72 years, mean 36.3. History of migraine was 12 years and history of daily headaches 3.1 years. Headache intensity was $7.7(0-10$ scale). Mean number of acute medications taken was 12.4 week.

Diagnosis of fibromyalgia was done according to the 1990 diagnostic criteria established by the American College of Rheumatology ${ }^{13}$. The Fatigue Severity Scale (FSS) (cut-off of 27 defined fatigue) and CDC (Center for Disease Control) diagnostic criteria for chronic fatigue syndrome (CFS) were used ${ }^{14}$. Insomnia was defined according to Diagnostic and Statistical Manual of Mental Disorders ${ }^{15}$. Acute medication overuse was defined according to Silberstein's diagnostic criteria ${ }^{1}$ and the revised International Classification of Headache Disorders ${ }^{12}$. The local ethics committee approved the protocol and consent form.

All patients evaluated filled out the Beck Depression Inventory (BDI). Depression severity was divided into 4 groups, none or minimal depression (0-9), mild (10-16), moderate (17-29), and severe depression (>30) according to standardized cut points ${ }^{16}$. The BDI is a self rating scale which evaluates 21 symptoms of depression (sadness, feeling of discourage, failure, dissatisfaction, guilt, punishment, disappointment, blaming themselves, suicidal thoughts, crying, irritability, loss of interest in people, difficulty in making decisions, changes in appearance, changes in work productivity, sleep problems, fatigue, loss of appetite, weight gain/loss, feeling worried, and, interest in sex). For each symptom patients rates themselves from $0,1,2$ or 3 . The maximum score is 63 and the minimum score is 0 .

The one-way ANOVA, student $t$ test for paired samples and Pearson's correlation tests were used for the statistical analysis. Results were considered statistically significant at $p<0.05$.

\section{RESULTS}

Sixty-three women $(90 \%)$ and 7 men (10\%) were studied. Age varied from 16 to 72 years, mean 36.3. History of migraine was 12 years and history of daily headaches 3.1 years. Headache intensity was 7.7. Mean number of acute medications taken was 12.4 week.

BDI ranged from 4 to 55 , mean $21 \pm 10.7 .58 .7 \%$ had moderate and severe depression (Table 1). At least some degree of depression (mild to severe) appeared in $85.8 \%$ of patients. The BDI scores correlated with perception of pain intensity $(p=0.02)$

Table 1. Depression severity in chronic migraine patients accord ing to Beck Depression Inventory.

\begin{tabular}{lc}
\hline Depression aspect & $\%$ \\
\hline Sadness & 81 \\
Felt discouraged & 46.7 \\
Felt like a failure & 44.3 \\
Dissatisfaction & 74.3 \\
Guilt & 51.4 \\
Punishment & 41.4 \\
Disappointed & 54.3 \\
Blamed themselves & 60 \\
Suicidal thoughts & 40 \\
Crying & 65.7 \\
Irritability & 84.3 \\
Loss of interest & 54.3 \\
Difficulty in making decisions & 54.3 \\
Changes in appearance & 37.1 \\
Changes in work productivity & 64.3 \\
Sleep problems & 64.3 \\
Fatigue & 81.4 \\
Loss of appetite & 48.6 \\
Weight gain/loss & 42.9 \\
Felt worried & 78.6 \\
\hline &
\end{tabular}


Table 2. Fibromyalgia, insomnia, fatigue and medication overuse and depression severity in chronic migraine patients.

\begin{tabular}{lllllll}
\hline $\begin{array}{l}\text { Depression } \\
\text { severity }\end{array}$ & $\begin{array}{l}\text { Beck } \\
\text { score }\end{array}$ & Total \% & $\begin{array}{l}\text { With/Without } \\
\text { Fibromyalgia (\%) }\end{array}$ & Insomnia (\%) & Fatigue (\%) & Med overuse (\%) \\
\hline Minimal/None & $0-9$ & 14.2 & $0 / 17.1$ & $3.8 / 15.8$ & $2.3 / 36.8$ & $11.5 / 8.3$ \\
Mild & $10-16$ & 27.1 & $21.7 / 31.8$ & $26.9 / 28.9$ & $20.5 / 31.6$ & $30.8 / 16.7$ \\
Moderate & $17-29$ & 37.2 & $47.8 / 34$ & $46.2 / 34.2$ & $47.7 / 15.8$ & $36.5 / 50$ \\
Severe & $>30$ & 21.5 & $30.5 / 17.1$ & $23.1 / 21.1$ & $29.5 / 15.8$ & $21.2 / 25$ \\
\hline
\end{tabular}

but not age, history of migraine, and acute medication consumption. Severe depression was found in $30.5 \%$ of patients with fibromyalgia compared to $17.1 \%$ of patients without fibromyalgia, $p<0.05$. Patients with fatigue (defined as a FSS score higher than 27) also reported severe depression significantly higher than those without fatigue ( 29.5 vs 15.8 respectively, $p<0.05$ ). No differences were found comparing patients with and without insomnia, as in patients with and without acute medication overuse (Table 2 ).

\section{DISCUSSION}

Depression is an important and frequent condition in primary care, neurology, tertiary and headache clinics settings ${ }^{6,7,16}$. It is estimated that depression may be responsible for as much as $25 \%$ of all visits to healthcare centers worldwide ${ }^{17}$. In primary care practices, $5-10 \%$ of adult patients experience major depression, making it one of the most common disorders seen by primary care physicians $^{18}$. Depression is associated with increased personal suffering, mortality, utilization of healthcare services and decreased functioning and quality of life ${ }^{19-21}$.

Recognizing and managing depression is a challenging task. It is unknown how recognition, management and outcomes of depression in headache, particularly chronic migraine patients, have been accessed in different settings, such as primary care, neurology or even headache centers. Headache patients are time consuming, and chronic daily headache, chronic migraine or refractory patients are complex with significant comorbidity with depression. The Beck Depression Inventory is a feasable instrument for the detection and assessment of severity of depression in chronic migraine patients. It is a self-applicable scale. It has an easy scoring and there is a correlation between DSM-IV diagnosis of major depression and the BDI scoring, a cut-off of 16 suggesting a major depression diagnosis ${ }^{22}$.

We found $21.5 \%$ of patients with severe depression. Patients with fibromyalgia and fatigue were more prone to have severe depression than those without them. Suicide is the most common causes of death in major depression patients. In our population $40 \%$ of patients reported suicidal ideation, $5 \%$ scoring the most severe item. Suicide risk and management has never been discussed in chronic migraine patients, future studies have to be carried out to address this important issue.

Certain symptoms including guilt, disappointment, difficulty in making decisions, irritability, disatisfaction can be rapidly assessed, which may be an useful therapeutic tool for the cognitive behavior approach. Sleep problems can also be screened, but further evaluation are needed for a specific diagnosis of sleep disorders. Work productivity information also gives chronic migraine and depression impact in the patient.

Fibromyalgia and fatigue are particular conditions predisposing severe depression in chronic migraine. Their recognition may have important implications in the CM management.

In conclusion, moderate to severe depression is common in chronic migraine. Suicidal ideation was reported by many patients, suicide risk assessment and management have to be addressed in chronic migraine. Other aspects such as sleep problems, sexual behavior, fatigue, irritability, guilt and work productivity may have implications in the chronic migraine management. The Beck Depression Inventory showed to be an easy tool to access depression severity and clinical aspects in chronic migraine patients. Fibromyalgia and fatigue predispose severe depression in chronic migraine, or depression predispose the others. Further studies are necessary to clarify better approaches for diagnostic and management purposes. 


\section{REFERENCES}

1. Silberstein SD, Lipton RB, Sliwinski M. Classification of daily and neardaily headaches: field trial of revised IHS criteria. Neurology 1996;47:871-875.

2. Castillo J, Munoz P, Guitera V, et al. Epidemiology of chronic daily headache in the general population. Headache 1998;39:190-196.

3. Mathew NT. Transformed migraine. Cephalalgia 1993;13:78-83.

4. Osterhaus JT, Gutterman DL, Plachetka JR. Healthcare resource and lost labour costs of migraine headache in the US. Pharmacoeconomics 1992;2:67-76.

5. Verri AP, Proietti CA, Galli C, et al. Psychiatric comorbidity in chronic daily headache. Cephalalgia 1998;18:45-49.

6. Mathew N. Chronic daily headache: clinical features and natural history. In Nappi G (ed). Headache and depression: serotonin pathways as a common clue. New York: Raven Press, 1991:49-58.

7. Peres MF, Zukerman E, Young WB, Silberstein SD. Fatigue in chronic migraine patients. Cephalalgia. 2002;22:720-724.

8. Peres MF, Young WB, Kaup AO, Zukerman E, Silberstein SD. Fibromyalgia is common in patients with transformed migraine. Neurology 2001;57:1326-1328.

9. Merikangas KR, Angst J, Isler H. Migraine and psychopathology: results of the Zurich cohort study of young adults. Arch Gen Psychiatry 1990;47:849-853.

10. Breslau N, Davis GC. Migraine, major depression and panic disorder: a prospective epidemiologic study of young adults. Cephalalgia 1992;12:85-90
11. Breslau N, Merikangas K, Bowden CL . Comorbidity of migraine and major affective disorders. Neurology 1994;44:17-S22

12. The International Classification of Headache Disorders. 2 Ed.Cephalalgia. 2004;24:1-160.

13. Wolfe F, Smythe HA, Yunus MB et al. The American College of Rheumatology 1990 Criteria for the Classification of Fibromyalgia. Report Multicenter Criteria Committee Arthritis Rheum 1990;33:160-172.

14. Brody, DS. Improving the management of depression in primary care: recent accomplishments and ongoing challenges. Disease Management \& Health Outcomes. 2003; 11:21-31.

15. American Psychiatric Association. Diagnostic and statistical manual of mental disorders. 4 Ed., Washington DC:APA Press, 1994

16. Beck AT, Ward CH, Mendelson M, Mock J, Erbaugh J. An inventory for measuring depression. Arch Gen Psychiatry. 1961;4,561-571.

17. Kleinman A, Cohen A. Psychiatry's global challenge. Sci Am 1997;3:86-89

18. Ballenger JC, Davidson JR, Lecrubier Y, et al. Consensus statement on the primary care management of depression from the International Consensus Group on Depression and Anxiety. J Clin Psychiatry. 1999;60:54-61.

19. Rovner BW, German PS, Brant LJ, et al. Depression and mortality in nursing homes. JAMA. 1991;265:993-996

20. Ormel J, VonKorff M, Ustun TB, et al. Common mental disorders and disability across cultures. JAMA. 1994; 272:1741-1748

21. Simon GE, Von Korff M, Barlow W. Health care costs of primary care patients with recognized depression. Arch Gen Psychiatry. 1995;52:850-856.

22. Lin EH, Katon WJ, Simon GE, et al. Achieving guidelines for the treatment of depression in primary care. Med Care.1997;35:831-842 